\title{
Study on Factor Decomposition of Per Capita Carbon Emissions from Household Energy Consumption in Guangdong Province Based on LMDI Method
}

\author{
HUANG Jiayu*, HE Junfei, XIE Zeqiong, LIANG Lijun, FENG Chao, XIAO Zhenqian, ZHONG Canming. \\ Guangzhou Institute of Energy Testing \\ Guangzhou 511447, China
}

\begin{abstract}
LMDI method is used to decompose the factors of per capita carbon emissions from household energy consumption of Guangdong province from 2008 to 2015. In this paper, the impact from economic growth, energy structure, energy intensity and energy-carbon emission intensity is explored and quantified. The results indicate that economic growth is the most important factor for the continuous per capita carbon emissions growth from household energy consumption, and energy-carbon emission intensity and energy intensity are the main factors to inhibit carbon emission growth. To achieve the reduction of carbon emission, the primary strategies in Guangdong province should be adjusting the energy structure, deep processing primary energy products, developing renewable clean energy, upgrading energy technologies, and improving energy efficiency.
\end{abstract}

Keywords-Carbon Emissions; Household Energy
Consumption; LMDI Method; Guangdong Province

\section{INTRODUCTION}

Since the 18th century, the industrial revolution has opened up an era of industrialization of human society, and the impact of human activities on climate and environment is increasing. Per capita energy consumption is an important aspect reflecting the economic development and living standards of a country or region. However, with the rapid economic development and continuous improvement of living standards, energy consumption increases rapidly, leading to a large amount of carbon dioxide emissions and some serious problems in resources and environment.

Since the problems of energy scarcity and climate change have become increasingly prominent, how to save energy and reduce emissions and how to address climate change issue have become the global hotspot of research. With the deepening of research on carbon emissions, related research on final carbon emissions from consumption of individual residents gradually arises. BIN et al. [1] found that, the US carbon emissions from household consumption account for $41 \%$ of all US carbon emissions. CHEN Yanling et al. [2] analysed the changes of per capita carbon emissions in China, and determined that economic growth is the main reason for the growth of carbon emissions in China. Xing Fangfang [3] estimated the final energy-carbon consumption of Beijing with the IPCC carbon emission coefficient method. Based on the above research and

* Fund Project: Low-carbon Development Special Fund Project of Guangdong Province (On Low-carbon Community Evaluation Index System of Guangdong Province); project funded by Guangzhou Municipal Bureau of Quality and Technical (No. 2017kj25、No.2017kj28)

First author and corresponding author: HUANG Jiayu (1991- ), female, postgraduate mainly engaged in energy saving and emission reduction research; E-mail:ziyuan2007@126.com, telephone: 020-62874716. some statistics, it is known that China's carbon emissions from household energy consumption is increasing year by year; its proportion in carbon emission is also increasing, and has become one of the major growth points of carbon emissions.

Guangdong province is a major Chinese province regarding economy and population, and a huge amount of energy is used there. In recent years, oil shortage has occurred for many times in Guangdong province, and shortage of electricity also appeared in summer. The environmental carrying capacity decreases dramatically, and the pressure on energy saving and emission reduction is great. This paper takes the changes of per capita carbon emissions from household energy consumption, population and energy consumption of Guangdong province from 2008 to 2015 relative to those of the base period (2008) as the research object. The LMDI model (Logarithmic Mean Divisia Index Method) is adopted so as to conduct a quantitative analysis from the aspects of economic development, energy structure, energy intensity and energycarbon emission intensity. The contribution of the above four factors on per capita carbon emissions from household energy consumption in Guangdong province is investigated, and suggestions on the energy saving and emission reduction strategies and development of low-carbon economy for Guangdong province are provided.

\section{RESEARCH METHODS}

KAYA [4] proposed the Kaya identical equation to address the problem of carbon emission factor decomposition, while ALBRECHT et al. [5] further explored based on the Kaya identical equation and proposed the decomposition formula of carbon emission:

$$
C=\sum_{i=1}^{n} \frac{C_{i}}{E_{i}} \times \frac{E_{i}}{E} \times \frac{E}{Y} \times \frac{Y}{P} \times P
$$

Wherein, $\mathrm{C}$ is the total energy emission in $\mathrm{kgCO}_{2 \mathrm{e}}$; $\mathrm{Ci}$ is the energy carbon emission $\mathrm{i}$ in $\mathrm{kgCO}_{2} ; \mathrm{E}$ is the total energy consumption in kgce; $\mathrm{E}_{\mathrm{i}}$ is the energy consumption i in kgce; $\mathrm{Y}$ is the gross domestic product in 100 million RMB; and $\mathrm{P}$ is the population in 10,000 people.

Therefore, the total carbon emissions from energy consumption is decomposed according to formula (1) as follows: 


$$
C^{t}=\sum_{i=1}^{n} \frac{C_{i}^{t}}{E_{i}^{t}} \times \frac{E_{i}^{t}}{E^{t}} \times \frac{E^{t}}{Y^{t}} \times \frac{Y^{t}}{P^{t}} \times P^{t}
$$

Wherein, $C^{t}$ is the total carbon emission from energy consumption in the period $t$ in $\mathrm{kgCO}_{2} ; C_{\mathrm{i}}^{\mathrm{t}}$ is the carbon emission $i$ from the energy consumption in the period $t$ in $\mathrm{kgCO} 2 \mathrm{e} ; E^{\mathrm{t}}$ is the total energy consumption in the period $t$ in kgce; $E_{\mathrm{i}}^{\mathrm{t}}$ is the energy consumption $i$ in the period $t$ in kgce; $Y^{\mathrm{t}}$ is the gross domestic product of the period $t$ in 100 million $\mathrm{RMB}$; and $P^{\mathrm{t}}$ is the population in the period $t$ in 10,000 people.

It can be obtained from the formula (2) that the per capita carbon emissions from household energy consumption in the period $t$ are:

$$
\begin{aligned}
A C^{t} & =\frac{C^{t}}{P^{t}}=\sum_{i=1}^{n} \frac{C_{i}^{t}}{E_{i}^{t}} \times \frac{E_{i}^{t}}{E^{t}} \times \frac{E^{t}}{Y^{t}} \times \frac{Y^{t}}{P^{t}} \\
& =\sum_{i=1}^{n} K_{i}^{t} S_{i}^{t} I^{t} R^{t}
\end{aligned}
$$

Wherein, $A C^{\mathrm{t}}$ is the total amount of per capita carbon emissions from household energy consumption in the period $t$ in $\mathrm{kgCO}_{2 \mathrm{e}} ; K_{\mathrm{i}}^{\mathrm{t}}$ is the energy-carbon intensity, that is, the carbon emission from the consumption of energy $i$ in the period $\mathrm{t} ; S_{\mathrm{i}}^{\mathrm{t}}$ is the energy structure, that is, the proportion of the consumption of energy $i$ in the period $t ; I^{t}$ is the energy intensity, that is, the energy consumption per unit of GDP in kgce/100 million RMB $R^{\mathrm{t}}$ is the economic development factor, that is, per capita GDP in 10,000 RMB/person.

The change of per capita carbon emissions from household energy consumption in the period $t$ relative to the base period (2008) is shown as follows:

$$
\begin{aligned}
\Delta A C=A C^{t}-A C^{0} & =\sum_{i=1}^{n} K_{i}^{t} S_{i}^{t} I_{i}^{t} R_{i}^{t}-\sum_{i=1}^{n} K_{i}^{0} S_{i}^{0} I_{i}^{0} R_{i}^{0} \\
& =\Delta A C_{K}+\Delta A C_{S}+\Delta A C_{I}+\Delta A C_{R}+\Delta A C_{r s d}
\end{aligned}
$$

Wherein, $\triangle A C_{\mathrm{K}}, \triangle A C_{\mathrm{S}}, \triangle A C_{\mathrm{I}}, \Delta A C_{\mathrm{R}}$ and $\triangle A C_{\mathrm{rsd}}$ are the variable factors of energy-carbon emission intensity, energy structure, energy intensity, and economic development as well as decomposition residue, in $\mathrm{kgCO}_{2 \mathrm{e}}$.

According to LMDI decomposition method and formula (4), the per capita carbon emissions from household energy consumption can be decomposed and the following formula is abtained:

$$
\begin{aligned}
\Delta A C_{K} & =\sum_{i=1}^{n} \frac{C_{i}^{t}-C_{i}^{o}}{\ln \left(\frac{C_{i}^{t}}{C_{i}^{0}}\right)} \cdot \ln \left(\frac{K_{i}^{t}}{K_{i}^{0}}\right), \Delta A C_{S}=\sum_{i=1}^{n} \frac{C_{i}^{t}-C_{i}^{o}}{\ln \left(\frac{C_{i}^{t}}{C_{i}^{0}}\right)} \cdot \ln \left(\frac{S_{i}^{t}}{S_{i}^{0}}\right), \Delta A C_{I}=\sum_{i=1}^{n} \frac{C_{i}^{t}-C_{i}^{o}}{\ln \left(\frac{C_{i}^{t}}{C_{i}^{0}}\right)} \cdot \ln \left(\frac{I^{t}}{I^{0}}\right), \\
D A C_{R} & =\sum_{i=1}^{n} \frac{C_{i}^{t}-C_{i}^{o}}{\ln \left(\frac{C_{i}^{t}}{C_{i}^{0}}\right)} \cdot \ln \left(\frac{R^{t}}{R^{0}}\right), \Delta A C_{r s d}=0
\end{aligned}
$$

The contribution rates of the influencing factors are defined as follows:

$$
\eta_{K}=\frac{\Delta A C_{K}}{\Delta A C}, \eta_{S}=\frac{\Delta A C_{S}}{\Delta A C}, \eta_{I}=\frac{\Delta A C_{I}}{\Delta A C}, \eta_{R}=\frac{\Delta A C_{R}}{\Delta A C}
$$

Wherein, $\eta_{\mathrm{K}}, \eta_{\mathrm{S}}, \eta_{\mathrm{I}}$ and $\eta_{\mathrm{R}}$ are the contribution rates of energy-carbon emission intensity, energy structure, energy intensity and economic development.

\section{DATA SELECTION AND EMPIRICAL ANALYSIS}

\section{A. Overview of research area and data source}

Guangdong province is located in the south of Chinese mainland, belonging to the east Asian monsoon region. Its main industries are manufacturing and tertiary industries. Guangdong is a promising province in economy, and its GDP ranks first in China for more than a decade. The energy data, population data and GDP data from 2008 to 2015 in this paper are mainly from the Statistical Yearbook of Guangdong Province of the past years, wherein the GDP data are based on the constant prices of 2008 .

\section{B. Accounting and analysis of carbon emission}

The carbon emissions of primary energy in this paper are mainly calculated according to Guideline for Reports of Carbon Dioxide Emission Information of Enterprises (Organizations) in Guangdong Province (Edition of 2014) [6], while the carbon emissions from electricity consumption are mainly calculated based on Emission Factors of Regional Power Grid Baseline in 2008-2015 of China [7].

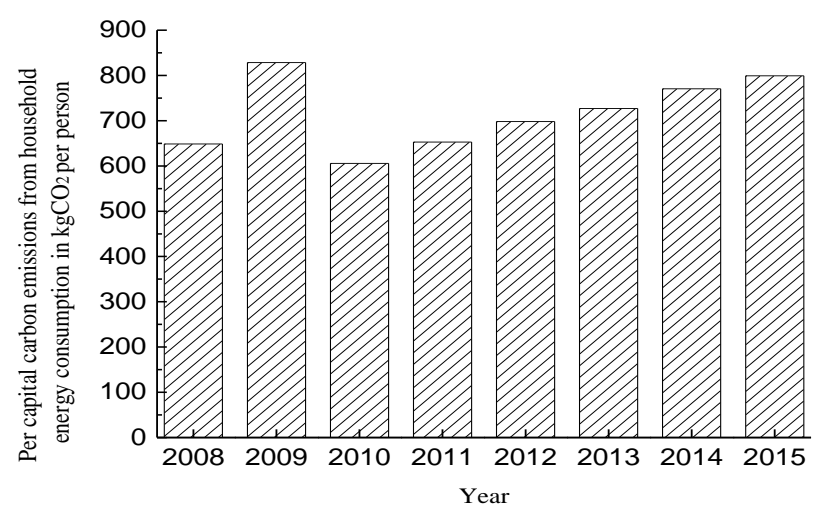

Fig. 1. Per Capita Carbon Emissions from Household Energy Consumption in Guangdong Province of 2008 2015

\section{Decomposition and analysis of influencing factors}

Taking the year of 2008 as the base period, the expanded Kaya's identical equition and LMDI model are adopted to decompose the per capita carbon emissions from household energy consumption in Guangdong province of 2008 2015. Moreover, the yearly contribution value and the yearly contribution rate of various influencing factors (Table 1 and Figure 2), accumulative contribution value of various 
influencing factors (Table 2) and the accumulative contribution rate of various factors in 2015 (Figure 3) are calculated.

As can be seen from Table 2 and Figure 3, the per capita carbon emissions from household energy consumption in Guangdong province increased by $541.79 \mathrm{~kg}$ from 2008 to 2015. The accumulative contribution values of energy-carbon emission intensity and energy intensity in Guangdong province are negative, while the accumulative contribution values of energy structure and economic development are positive. Based on the accumulative contribution values, it is shown that the changes of energy-carbon emission intensity and energy intensity have a negative impact on the increase of per capita carbon emissions from household energy consumption, while the changes of energy structure and economic development have a positive impact on the increase of carbon emission. Wherein, the most significant impact is from the economic development factor, which results in a carbon emission increase of $1348.76 \mathrm{~kg}$ and has an uplifting effect of $248.95 \%$ for accumulative carbon emission increase; energy-carbon emission intensity also has a great impact on carbon emission, which results in a carbon emission decrease of $706.83 \mathrm{~kg}$ with an accumulative contribution rate of $-130.46 \%$. In contrast, the factors of energy structure and energy intensity have less effect on the increase of carbon emission, resulting in increases of $38.06 \mathrm{~kg}$ and $-138.20 \mathrm{~kg}$ with accumulative contribution rates of $7.02 \%$ and $-25.51 \%$ respectively.

As can be seen from Table 1 and Figure 2, from the perspectives of yearly contribution value and yearly contribution rate, the economic development is the most significant factor causing the growth of per capita carbon emissions from household energy consumption, and its contribution to the growth of per capita carbon emissions from household energy consumption is obviously greater than the contribution of inhibiting factors. The curve of economic development has a decisive effect on the curve trend of per capita carbon emissions growth. A positive effect is shown for each year and a trend of increasing year by year is presented. It is shown that economic development has a significant and continuous uplifting effect on the growth of per capita carbon emissions from household energy consumption in Guangdong province.

The decrease of energy carbon emission intensity has a significant inhibitory effect on the growth of per capita carbon emissions from household energy consumption. As can be seen from Figure 2 and Table 2, the trend of factors of carbon emissions from electricity consumption is substantially consistent with the curve of energy intensity. This is because electricity accounts for a major proportion $(60 \%)$ of household energy consumption in Guangdong province. As the "converting oil to gas" project, photovoltaic power generation, energy management system construction of power plants are carried out, the effects on energy saving and consumption reduction are significant, and intensity of carbon emissions from electricity consumption decreases, promoting the decline in per capita carbon emissions from household energy consumption. The decrease of energy intensity represents the increase of energy utilization efficiency. The impact of energy intensity shows a positive correlation first and then a negative correlation, and the inflection point appears in 2010. The reason may be: the publishing of a series of standards and regulations related to construction energy saving, such as Design Standard on Energy Efficiency of Residential Buildings in zone of Hot Summer and Warm Winter (JGJ 75-2012) and the unveiling of energy efficiency standards for dozens of products such as air conditioners, lighting applicants and refrigerators in this period. These standards has an inhibitory effect on the increase of carbon emissions due to energy intensity after 2010. The contribution of energy intensity fluctuates, indicating that the energy intensity is not steadily reduced, energy efficiency is not high, and there is still some room for improvement of the existing technologies.

TABLE I. YEARLY CONTRIBUTION VALUE AND YEARly CONTRIBUTION RATE OF VARIOUS FACTORS ON PER CAPITA CARBON EMISSIONS FROM HOUSEHOLD ENERGY CONSUMPTION IN GUANGDONG PROVINCE

\begin{tabular}{|c|c|c|c|c|c|c|c|c|c|c|}
\hline \multirow[b]{2}{*}{ Index } & \multicolumn{5}{|c|}{ Yearly contribution value $\left(\mathrm{kgCO}_{2 \mathrm{e}}\right)$} & \multicolumn{5}{|c|}{ Yearly contribution rate $(\%)$} \\
\hline & $\begin{array}{l}\text { Energy-carbon } \\
\text { emission } \\
\text { intensity }\end{array}$ & $\begin{array}{l}\text { Energy } \\
\text { structure }\end{array}$ & $\begin{array}{l}\text { Energy } \\
\text { intensity }\end{array}$ & $\begin{array}{l}\text { Economic } \\
\text { development }\end{array}$ & Overall & $\begin{array}{l}\text { Energy-carbon } \\
\text { emission intensity }\end{array}$ & $\begin{array}{l}\text { Energy } \\
\text { structure }\end{array}$ & $\begin{array}{l}\text { Energy } \\
\text { intensity }\end{array}$ & $\begin{array}{l}\text { Economic } \\
\text { development }\end{array}$ & Overall \\
\hline 2009 & -44.39 & 2.50 & 160.95 & 60.82 & 179.89 & -24.68 & 1.39 & 89.47 & 33.81 & 100 \\
\hline 2010 & -75.41 & 4.46 & -46.72 & 74.89 & -42.78 & 176.29 & -10.42 & 109.21 & -175.08 & 100 \\
\hline 2011 & -130.17 & 0.57 & -1.17 & 135.07 & 4.29 & -3031.78 & 13.20 & -27.31 & 3145.89 & 100 \\
\hline 2012 & -119.77 & 4.66 & -22.48 & 186.97 & 49.38 & -242.55 & 9.44 & -45.53 & 378.63 & 100 \\
\hline 2013 & -112.38 & 3.11 & -55.39 & 243.25 & 78.58 & -143.02 & 3.96 & -70.49 & 309.56 & 100 \\
\hline 2014 & -101.98 & 15.70 & -89.02 & 297.10 & 121.79 & -83.73 & 12.89 & -73.09 & 243.93 & 100 \\
\hline 2015 & -122.73 & 7.06 & -84.36 & 350.66 & 150.63 & -81.47 & 4.69 & -56.01 & 232.79 & 100 \\
\hline
\end{tabular}




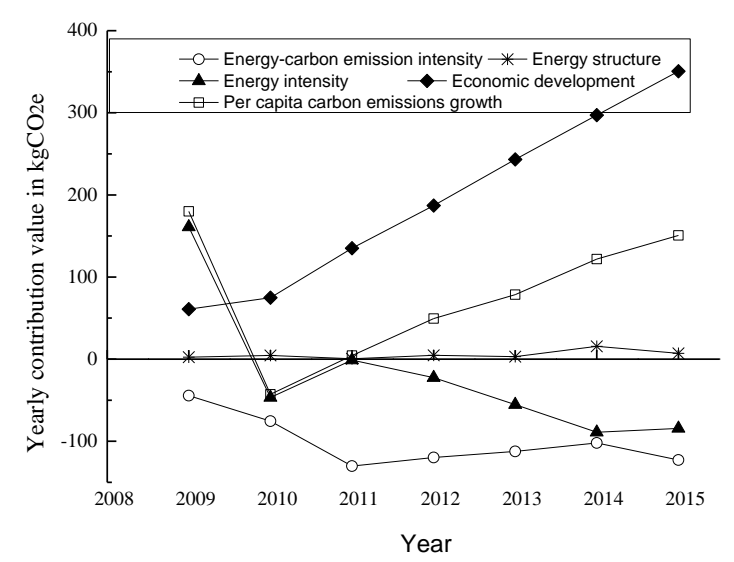

Fig. 2. Yearly Contribution Value of Various Factors on Per capita carbon emissions from Household Energy Consumption in Guangdong Province of 2008 2015

It can be known from the factor decomposition that under the premise of meeting the people's household demand for energy, promoting energy conservation and emission reduction has become an urgent task. Given that Guangdong's economy will maintain a relatively high growth in the near future, it is unrealistic to try to control carbon emissions by reducing the pace of economic development. To reduce per capita carbon emissions from household energy consumption in Guangdong province, energy structure adjustment, deep processing of primary energy products [8], development of renewable clean energy, upgrading of energy technologies and improvement of energy efficiency are required. Optimization of energy structure in the power grid and increasing of the clean energy proportion are also important means to reduce carbon emission. The power of Guangdong province is from China Southern Power Grid. From a consumption point of view, the relation between the energy in power generation and carbon emissions from household energy consumption is weak. However, by raising the proportion of clean energy in the electricity power of Guangdong province and reducing the carbon emission of the entire power grid, the per capita carbon emissions from household energy consumption are reduced.

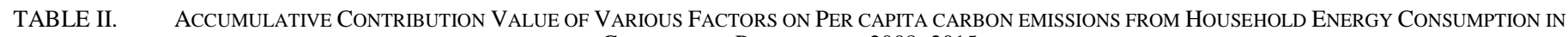
GUANGDONG PROVINCE OF 2008 2015

\begin{tabular}{|c|c|c|c|c|c|}
\hline \multirow{2}{*}{ Index } & \multicolumn{5}{|c|}{ Accumulative contribution value $\left(\mathrm{kgCO}_{2 \mathrm{e}}\right)$} \\
\hline & Energy-carbon emission intensity & Energy structure & Energy intensity & Economic development & Overall \\
\hline 2009 & -44.39 & 2.50 & 160.95 & 60.82 & 179.89 \\
\hline 2010 & -119.80 & 6.96 & 114.24 & 135.71 & 137.11 \\
\hline 2011 & -249.97 & 7.53 & 113.06 & 270.79 & 141.41 \\
\hline 2012 & -369.74 & 12.19 & 90.58 & 457.75 & 190.78 \\
\hline 2013 & -482.13 & 15.30 & 35.19 & 701.00 & 269.36 \\
\hline 2014 & -584.11 & 31.00 & -53.84 & 998.10 & 391.16 \\
\hline 2015 & -706.83 & 38.06 & -138.20 & 1348.76 & 541.79 \\
\hline
\end{tabular}

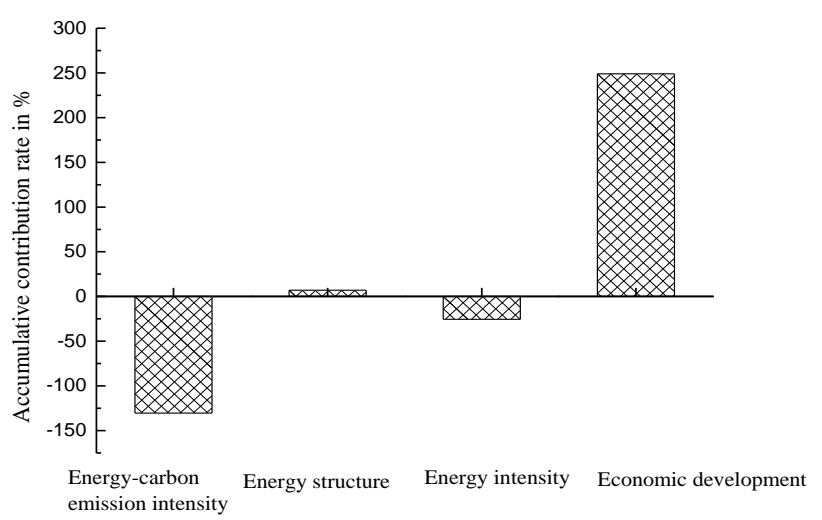

Fig. 3. Accumulative Contribution Rate of Various Factors on Per Capita Carbon Emissions from Household Energy Consumption in Guangdong Province of 2015

\section{CONCLUSION}

In this paper, the LDMI model is adopted for the decomposition of per capita carbon emissions from household energy consumption in Guangdong province. Through empirical analysis, the following conclusions are reached:

(1) Taking the year of 2008 as the base period, the accumulative contribution of economic development and energy structure till 2015 is positive, while the accumulative contribution of energy-carbon emission intensity and energy intensity till 2015 is negative.

(2) Economic development is the main promoting factor for the increase of per capita carbon emissions from household energy consumption in Guangdong province, and its contribution to the growth of per capita carbon emissions from household energy consumption is obviously greater than that of inhibitory factors.

(3) Energy-carbon emission intensity and energy intensity are important inhibitory factors on the growth of per capita 
carbon emissions from household energy consumption in Guangdong province. Meanwhile, due to the contribution of new energy technologies and the publishing of standards and regulations, energy efficiency has been improved and the growth rate of carbon emission has slowed down.

(4) It is estimated that the economy in Guangdong province will maintain a rapid growth for a long period. During this time, energy supply will become the bottleneck of rapid economic development. It is necessary to optimize and upgrade energy technologies, adjust energy structure and effectively guide the economy to a path of low-carbon and sustainable development.

\section{REFERENCES}

[1] BIN S,DOWLATABADI H.Consumer lifestyle approach to US energy use and the related CO2 emissions[J]. Energy Policy, 2005, 33(2) :197208.

[2] CHEN Yanling, Wang Chen. The correlation analysis of carbon emission and economic growing in China[J].Journal Of Beijing Institute Of Petro-Chemical Technology, 2009, 17(2) :54-58.

[3] XING Fangfang, OUYANG Yunzhi, Wang Xiaoke. Inventory of final energy-carbon consumption and its structure in Beijing[J].Chinese Journal of Environmental Science, 2007(9) :1918-1922.

[4] KAYA Y. Impact of carbon dioxide emission on GNP growth: interpretation of proposed scenarios[J].Paris: Presentation to the energy and industry subgroup, response strategies working group, IPCC, 1989.

[5] ALBRECHT J,FRANCOIS D,SCHOORS K.A Shapley decomposition of carbon emissions without residuals[J].Energy Policy, 2002, 30(9): 727-736.

[6] Development and Reform Commission of Guangdong province. Guideline for reports of carbon dioxide emission information of enterprises (organizations) in Guangdong province (edition of 2014) [Z]. 2015-02-06

[7] State Development and Reform Commission of People's Republic of China.Emission Factors of Regional Power Grid Baseline in 2008-2015 of China [Z]. 2008 2015.

[8] HE Renfei, NIU Shuwen, JIA Yanqin, et al. Panel data analysis of per capita household energy consumption, income and carbon emissions[J]. Resources Science, 2012,34(6): 1142-1151. 